Original article

\title{
Receipt of public assistance during childhood and hypertension risk in adulthood
}

\author{
Debbie S. Barrington PhD, MPH ${ }^{\mathrm{a}, *}$, Sherman A. James $\mathrm{PhD}^{\mathrm{b}}$ \\ ${ }^{a}$ Department of Human Science, Georgetown University Medical Center, Washington, DC \\ ${ }^{\mathrm{b}}$ Department of Epidemiology, Rollins School of Public Health, Emory University, Atlanta, GA
}

\section{A R T I C L E I N F O}

Article history:

Received 31 May 2016

Accepted 27 November 2016

Available online 9 December 2016

\section{Keywords:}

African Americans

Hypertension

Public assistance

Poverty

Public policy

\begin{abstract}
A B S T R A C T
Purpose: We examined if receipt of public assistance during childhood lowered risk for hypertension by mid-life in a cohort of African Americans in the Southeastern United States.

Methods: We used multiple logistic regression models to assess the relationship between receipt of public assistance during childhood and adult hypertension among 405 male and 737 female adult participants enrolled between 1988 and 2001 in the Pitt County Study, a community-based prospective cohort study of African Americans in North Carolina. Statistical analyses were adjusted for child and adult sociodemographic measures as well as adult psychosocial and lifestyle factors.

Results: Women who grew up in economically disadvantaged families and who received public assistance during childhood had a $66 \%$ decreased odds of hypertension by mid-life compared with women similarly disadvantaged in childhood but who did not receive public assistance, odds ratio $=0.34 ; 95 \%$ confidence interval: 0.14-0.83. No association was observed for African American men.

Conclusions: Receipt of anti-poverty federal assistance during childhood was associated with reduced risk for hypertension by mid-life among African American women. It is possible that social expenditures on public assistance programs for families in need could produce long-term health benefits for children.
\end{abstract}

(c) 2016 Elsevier Inc. All rights reserved.

\section{Introduction}

In addition to rising income inequality and decreasing median household income, the United States has also seen in recent decades an increase in the number of families participating in public assistance programs, including the Supplemental Nutrition Assistance Program, Temporary Assistance for Needy Families, General Assistance, Housing Assistance, Medicaid, and Supplemental Security Income [1,2]. In 2012, for example, approximately 52.2 million Americans received means-tested federal assistance each month [2]. Children have the most need for a social safety net, given that the average monthly participation in governmental assistance programs was 39\% among children aged less than 18 years in 2012 [2].

Only $61 \%$ of families in poverty, as defined by household income below standard thresholds adjusted for inflation [1], received federal assistance in 2012. This was the case despite clear evidence of improved psychosocial, cognitive, and health outcomes among socioeconomically disadvantaged children who

\footnotetext{
* Corresponding author. Department of Human Science, Georgetown University Medical Center, 253 St. Mary's Hall, 3700 Reservoir Road NW, Washington, DC 20057-1107. Tel.: +1 202-687-4211; fax: +1 202-687-5553.

E-mail address: debbie.barrington@georgetown.edu (D.S. Barrington).
}

participate in public assistance programs such as the Food Stamp Program and the Special Supplemental Nutrition Program for Women, Infants, and Children [3-5]. In addition, results from an economic study indicate that childhood participation in public assistance programs could provide a long-lasting positive impact on cardiovascular health, specifically lowering the risk of developing metabolic syndrome in adulthood [6]. This finding underscores the importance of continued research into the potential contribution of federal antipoverty programs to foster better health across the life course.

African Americans have the lowest median household income, the highest prevalence of unemployment and childhood poverty $[1,7]$, and the highest prevalence of hypertension relative to other US racial-ethnic groups: $44.9 \%$ for men and $46.1 \%$ for women [8]. These multiple disadvantages faced by African Americans underscore the need for studies that shed light on social policies that not only diminish the severity of socioeconomic distress in this population, but which may also lower long-term risk for chronic diseases, such as high blood pressure (BP). In the present study, we investigated whether receipt of public assistance during childhood, in the face of need, was associated with decreased risk for adult hypertension in a Southern African American cohort. 


\section{Materials and methods}

\section{Sample}

The Pitt County Study (PCS) is a community-based, probability sample of African Americans in eastern North Carolina who were initially interviewed in 1988 and reinterviewed in 2001. The original study objective was to examine the contribution of social, economic, psychological, and behavioral risk factors for hypertension and related disorders in working and middle-class African Americans aged 25-50 years in 1988 [9-12]. At baseline, neighborhoods with high concentrations of African Americans, especially those with middle class African Americans, were oversampled to insure a socioeconomically diverse study population [13]. The research protocol was approved by the Human Subjects Institutional Review Board of the University of Michigan.

The 1988 baseline sample included 1773 African Americans (661 women and 1112 men). In 2001, information on life course social and economic resources from early childhood through 2001 was obtained via interview for 1221 (428 men and 793 women). Further details on the 1988 baseline sample and household interview and the 2001 follow-up interview can be found elsewhere [12,13]. Analyses for the present study were based on 405 men and 737 women who had complete exposure and outcome data.

\section{Measures}

\section{Blood pressure}

Hypertension, defined as a systolic BP of $140 \mathrm{~mm} \mathrm{Hg}$ or greater, and/or a diastolic BP of $\geq 90 \mathrm{~mm}$ Hg or greater, and/or currently taking anti-hypertensive medication in 1988 was the study outcome. BP in 1988 was measured by a standard mercury sphygmomanometer on the study participant's right arm; three BP readings were taken. For analytical purposes, BP was defined as the average of the second and third readings. The fifth-phase Korotkoff sound indicated diastolic BP.

\section{Childhood sociodemographic measures}

In 2001, a computerized Event History Calendar (EHC) was administered to the PCS study participants to measure the childhood social environment. The EHC maximizes recall accuracy of distant autobiographical information using more easily remembered landmark events (e.g., name and residence of the primary parental figure at a given age, year started school, age at first paid job, and so on) to ease recollection of more easily forgotten experiences [14,15]. The EHC assessed receipt of childhood public assistance, "yes" versus "no," and childhood household deprivation, defined by any occurrence of food insecurity, lack of heat, electricity, or plumbing from birth to 13 years of age. The primary exposure variable was a three-category measure combining information on childhood public assistance and childhood household deprivation: (1) receipt of public assistance, (2) no receipt of public assistance/household deprivation, and (3) no receipt of public assistance/no household deprivation.

Other childhood socio-familial variables were included as covariates to estimate the independent influence of childhood receipt of public assistance on hypertension in early-middle adulthood. Residence from birth through age of 18 years in a twoadult household (yes vs. no) characterized family structure composition. Stability of parental guardianship was determined by the number of guardianship changes from birth to 18 years of age (none vs. any) and was dichotomized into "yes" versus "no." Two measures were used to define childhood socioeconomic position from birth to 13 years of age: parental occupation, denoted by the highest ranking job held by a parental guardian of either sex, with jobs categorized as "skilled," "farmer," and "unskilled or housewife," and parental education, defined by the highest level of education of a parent/guardian of either sex, with education categorized as "less than high school $(<\mathrm{HS})$," "high school or greater (HS+)," and "missing" [12].

\section{Adult measures}

Covariates used for statistical adjustment included demographic information, socioeconomic position, health behaviors, anthropometry, and psychosocial factors measured in 1988. Demographics included age and marital status, specified as married "yes" versus "no." Measures of socioeconomic position were education ( $<\mathrm{HS}$, HS, and $>$ HS), currently unemployed (yes vs. no), and occupation (laborers, operatives/blue collar and craft/white collar) [12].

Table 1

Selected characteristics of study participants lost to follow-up and in the final analytic sample: the Pitt County, North Carolina Study

\begin{tabular}{|c|c|c|c|c|c|c|}
\hline \multirow[t]{2}{*}{ Variable } & \multicolumn{3}{|l|}{ Men } & \multicolumn{3}{|l|}{ Women } \\
\hline & $\begin{array}{l}\text { Nonresponders } \\
(n=256)\end{array}$ & $\begin{array}{l}\text { Analytic sample } \\
(n=405)\end{array}$ & $P$ value ${ }^{*}$ & $\begin{array}{l}\text { Nonresponders } \\
(n=375)\end{array}$ & $\begin{array}{l}\text { Analytic sample } \\
(n=737)\end{array}$ & $P$ value ${ }^{*}$ \\
\hline Age, mean (SE) & $35.75(0.46)$ & $36.16(0.35)$ & .4753 & $35.17(0.35)$ & $36.20(0.27)$ & .0224 \\
\hline Married, \% & 48.44 & 62.62 & .0003 & 38.93 & 41.79 & .3594 \\
\hline Unemployed, \% & 11.72 & 6.17 & .0119 & 20.27 & 17.10 & .1949 \\
\hline Education, \% & & & .6072 & & & .9908 \\
\hline$<\mathrm{HS}$ & 32.03 & 31.60 & & 30.13 & 30.53 & \\
\hline HS & 41.02 & 38.02 & & 40.53 & 40.30 & \\
\hline$>\mathrm{HS}$ & 26.95 & 30.37 & & 29.33 & 29.17 & \\
\hline Occupation, \% & & & .1462 & & & .3172 \\
\hline Laborer & 33.47 & 26.43 & & 36.69 & 36.80 & \\
\hline Operatives & 31.47 & 33.42 & & 30.81 & 34.66 & \\
\hline Craft/white collar & 35.06 & 40.15 & & 32.49 & 28.53 & \\
\hline BMI $\left(\mathrm{kg} / \mathrm{m}^{2}\right)$, mean $(\mathrm{SE})$ & $25.78(0.25)$ & $26.45(0.22)$ & .0524 & $28.81(0.36)$ & $29.47(0.25)$ & .1259 \\
\hline WHR, mean (SE) & $0.88(0.004)$ & $0.89(0.003)$ & .6562 & $0.86(0.004)$ & $0.85(0.003)$ & .3550 \\
\hline Smoker, \% & 51.97 & 44.20 & .0518 & 33.33 & 34.10 & .7976 \\
\hline Physically active, \% & 53.33 & 58.02 & .2369 & 32.89 & 36.29 & .2622 \\
\hline Drinker, \% & 60.55 & 62.47 & .6204 & 42.40 & 38.53 & .2132 \\
\hline High John Henryism, \% & 46.09 & 48.64 & .5228 & 46.93 & 48.03 & .7286 \\
\hline High instrumental support, \% & 25.00 & 33.83 & .0163 & 28.53 & 30.53 & .4917 \\
\hline High emotional support, \% & 35.69 & 34.57 & .7693 & 39.47 & 41.79 & .4563 \\
\hline High stress, \% & 24.71 & 17.12 & .0179 & 28.27 & 29.72 & .6156 \\
\hline Hypertension, \% & 30.08 & 32.35 & .5408 & 24.40 & 25.10 & .7974 \\
\hline
\end{tabular}

$\mathrm{SE}=$ standard error; WHR $=$ waist-hip ratio.

$* \chi^{2}$ test (\%), $t$ test (mean) of difference. 
Health behaviors included smoking status, dichotomized as "current smoker/nonsmoker," alcohol consumption dichotomized as "current drinker/nondrinker," and physical activity, denoted by a response (yes vs. no) to the question, "do you exercise at least 3 times per week sufficient to breathe hard and sweat?" Anthropometric indices were the ratio of waist-to-hip circumference, and body mass index (BMI) calculated as weight (kilogram) divided by the square of the height (square meter) [13].

Psychosocial covariates included John Henryism, defined as a strong behavioral predisposition to engage in high-effort coping with difficult social and economic stressors. Measured via the 12item John Henryism Active Coping Scale, total scores were divided at the median (high vs. low) for analytical purposes [16]. Instrumental social support was measured by a 6 -item scale, and emotional support was measured by a 3-item scale; both were dichotomized (always/most of the time vs. sometimes/never) [13]. Perceived Stress, a correlate of BP in the PCS, was measured by an 8item scale [17], with scores dichotomized at the median (low vs. high) for analytic purposes.

\section{Analysis}

Analyses were weighted to account for the oversampling of middle-class households at baseline and nonresponse to both the 1988 and 2001 surveys and thus provided more conservative estimates of standard errors [18]. The characteristics of study participants were described using means for continuous variables and proportions for categorical variables. To estimate associations between adult hypertension and the public assistance and household deprivation measure, multiple logistic regression models were used. Because of a statistically significant sex interaction term $(P$ value $<.0001)$, sex-stratified results are presented. Logistic regression was performed to add early life and more proximal risk covariates individually, or as a group, to assess their contributions to the odds for hypertension. Odds ratios (ORs) and 95\% confidence intervals (CIs) are reported. Statistical significance was set at $\alpha=0.05$ level, two-tailed tests. All analyses were performed using SAS software (version 9.4; SAS Institute, Inc., Cary, NC).

Table 2

Selected characteristics by childhood public assistance of African American men: the Pitt County, North Carolina Study

\begin{tabular}{|c|c|c|c|c|}
\hline \multirow[t]{2}{*}{ Variable } & \multicolumn{4}{|l|}{ Men $(n=405)$} \\
\hline & $\begin{array}{l}\text { Public assistance } \\
(n=51)\end{array}$ & $\begin{array}{l}\text { No public assistance/HH } \\
\text { deprivation }(n=233)\end{array}$ & $\begin{array}{l}\text { No public assistance/no } \mathrm{HH} \\
\text { deprivation }(n=121)\end{array}$ & $P$ value ${ }^{*}$ \\
\hline \multicolumn{5}{|l|}{ Childhood $^{\dagger}$} \\
\hline HH deprivation, mean (SE) & $1.36(0.15)$ & $1.47(0.05)$ & - & .4776 \\
\hline Intact family, $\%$ & 65.27 & 88.45 & 82.81 & .0018 \\
\hline Two adult household, $\%$ & 36.84 & 70.65 & 54.70 & .0001 \\
\hline Parent/guardian education, $\%$ & & & & .0116 \\
\hline Missing & 27.92 & 35.97 & 18.00 & \\
\hline$<\mathrm{HS}$ & 50.90 & 42.33 & 43.99 & \\
\hline HS+ & 21.18 & 21.70 & 38.01 & \\
\hline Parent/guardian occupation, ${ }^{\S} \|$ \% & & & & .0002 \\
\hline Skilled & 12.71 & 12.03 & 29.23 & \\
\hline Farmer & 32.13 & 40.70 & 15.26 & \\
\hline Unskilled/housewife & 55.16 & 47.27 & 55.50 & \\
\hline \multicolumn{5}{|l|}{ Adulthood } \\
\hline Age, mean (SE) & $31.66(0.94)$ & $36.37(0.52)$ & $33.45(0.69)$ & $<.0001$ \\
\hline Married,\% & 68.24 & 61.20 & 56.50 & .4714 \\
\hline Unemployed,\% & 10.17 & 5.37 & 4.44 & .4163 \\
\hline Education, \% & & & & .0048 \\
\hline$<\mathrm{HS}$ & 44.89 & 33.03 & 24.20 & \\
\hline HS & 27.86 & 44.39 & 33.45 & \\
\hline$>\mathrm{HS}$ & 27.25 & 22.59 & 42.35 & \\
\hline Occupation, ${ }^{\pi} \%$ & & & & .8700 \\
\hline Laborer & 29.02 & 28.35 & 22.88 & \\
\hline Operatives & 30.56 & 34.07 & 33.92 & \\
\hline Craft/white collar & 40.42 & 37.57 & 43.20 & \\
\hline BMI $\left(\mathrm{kg} / \mathrm{m}^{2}\right)$, mean $(\mathrm{SE})$ & $27.49(0.75)$ & $26.38(0.31)$ & $25.55(0.40)$ & .0546 \\
\hline WHR, mean (SE) & $0.89(0.01)$ & $0.89(0.00)$ & $0.90(0.01)$ & .6505 \\
\hline Smoker, \% & 46.61 & 42.79 & 52.48 & .3449 \\
\hline Physical activity, \% & 72.86 & 60.05 & 59.01 & .2938 \\
\hline Drinker,\% & 67.10 & 60.61 & 70.87 & .2524 \\
\hline High instrumental support, $\%$ & 19.00 & 37.29 & 33.36 & .0747 \\
\hline High emotional support," \% & 20.70 & 32.33 & 37.32 & .1792 \\
\hline High John Henryism, ${ }^{* *} \%$ & 54.89 & 44.16 & 49.69 & .4124 \\
\hline High stress, ${ }^{* *} \%$ & 31.93 & 40.30 & 44.08 & .4556 \\
\hline Hypertension, \% & 29.46 & 33.62 & 28.26 & .6406 \\
\hline
\end{tabular}

$\mathrm{HH}=$ household; $\mathrm{SE}=$ standard error; $\mathrm{WHR}=$ waist-to-hip ratio.

Data were weighted for oversampling and nonresponse.

* Rao-Scott $\chi^{2}$ test for comparison (\%), $t$ test (mean) of difference.

Measured in 2001 via Event History Calendar.

$\ddagger$ Birth to 18 years.

$\S$ Birth to 13 years.

" US Census Occupations, (see [7] for full citation).

ฯ Hollingshead Scale (see [7] for full citation).

\# Support always/most of the time.

** Score above the median. 


\section{Results}

Differences in selected characteristics between those lost to follow-up and those who completed the early childhood assessment in 2001 for the current analyses are summarized in Table 1. Among men, those lost to follow-up were more disadvantaged, in that they had a higher prevalence of unemployment, smoking, high stress, and lower levels of instrumental support than men who remained in the final analytic sample. Among women, with the exception of age, there were no differences between those lost to follow-up and those in the analytic sample. There was no difference in the prevalence of hypertension between nonresponders and the final study participants.

As shown in Table 2, men who received public assistance were least likely to live as a child within an intact family and two-adult household and were most likely to have parents who attained less than a high school education compared with those who did not receive public assistance during childhood. In adulthood, they were most likely to attain low levels of education and have the highest mean BMI. There was no significant difference in mean childhood household deprivation score between men who received public assistance during childhood and those who did not receive public assistance but who, nevertheless, reported household material deprivation.

Women who received public assistance also experienced the highest levels of disadvantage in the other childhood socio-familial factors compared with those who did receive public assistance during childhood (Table 3). There was also no significant difference in mean household deprivation score between women who received public assistance during childhood and those who did not receive public assistance but nevertheless reported household material deprivation.

ORs for associations between childhood public assistance and adult hypertension are summarized in Table 4 for men and Table 5 for women. No significant association was found between childhood public assistance and adult hypertension among men; unadjusted OR $=0.82,95 \% \mathrm{CI}: 0.39-1.75$ and covariate-adjusted (model 5) $\mathrm{OR}_{\mathrm{adj}}=0.92,95 \% \mathrm{CI}$ : 0.39-2.16. No significant association was found for men who grew up in families that neither received public assistance nor experienced household deprivation compared to men from socioeconomically deprived households that did not receive public assistance; unadjusted $\mathrm{OR}=0.78,95 \% \mathrm{CI}$ : $0.45-1.35$ and fully adjusted $\mathrm{OR}_{\mathrm{adj}}=1.06,95 \% \mathrm{CI}$ : $0.56-2.01$.

Table 3

Selected characteristics by childhood public assistance of African American women: the Pitt County, North Carolina Study

\begin{tabular}{|c|c|c|c|c|}
\hline \multirow[t]{2}{*}{ Variable } & \multicolumn{4}{|l|}{ Women $(n=737)$} \\
\hline & $\begin{array}{l}\text { Public assistance } \\
(n=73)\end{array}$ & $\begin{array}{l}\text { No public assistance/HH } \\
\text { deprivation }(n=430)\end{array}$ & $\begin{array}{l}\text { No public assistance/no } \mathrm{HH} \\
\text { deprivation }(n=234)\end{array}$ & $P$ value \\
\hline \multicolumn{5}{|l|}{ Childhood $^{\dagger}$} \\
\hline HH deprivation, mean (SE) & $1.27(0.13)$ & $1.45(0.03)$ & - & .1814 \\
\hline Intact family, \% & 72.51 & 83.13 & 85.69 & .1097 \\
\hline Two-adult household, $\%$ & 44.50 & 68.02 & 56.78 & .0011 \\
\hline Parent/guardian education, ${ }^{\S, \|} \%$ & & & & .0017 \\
\hline Missing & 18.29 & 25.79 & 19.80 & \\
\hline$<\mathrm{HS}$ & 61.60 & 58.56 & 48.81 & \\
\hline HS+ & 20.11 & 15.65 & 31.39 & \\
\hline Parent/guardian occupation, ${ }^{\S, \|} \%$ & & & & $<.0001$ \\
\hline Skilled & 28.57 & 10.78 & 25.02 & \\
\hline Farmer & 13.71 & 44.86 & 20.06 & \\
\hline Unskilled/housewife & 57.71 & 44.36 & 54.91 & \\
\hline \multicolumn{5}{|l|}{ Adulthood } \\
\hline Age, mean (SE) & $34.25(0.98)$ & $36.74(0.42)$ & $32.99(0.45)$ & $<.0001$ \\
\hline Married, \% & 36.45 & 47.12 & 36.03 & .0368 \\
\hline Unemployed, \% & 15.36 & 14.85 & 16.92 & .8330 \\
\hline Education, \% & & & & .0040 \\
\hline$<\mathrm{HS}$ & 27.55 & 32.94 & 17.39 & \\
\hline HS & 39.44 & 40.25 & 44.05 & \\
\hline$>\mathrm{HS}$ & 33.01 & 26.81 & 38.56 & \\
\hline Occupation, ${ }^{\mp} \%$ & & & & .3785 \\
\hline Laborer & 39.91 & 34.09 & 29.93 & \\
\hline Operatives & 30.81 & 36.98 & 33.01 & \\
\hline Craft/white collar & 29.28 & 28.93 & 37.05 & \\
\hline BMI $\left(\mathrm{kg} / \mathrm{m}^{2}\right)$, mean $(\mathrm{SE})$ & $28.14(0.82)$ & $29.97(0.40)$ & $28.65(0.48)$ & .0362 \\
\hline WHR, mean (SE) & $0.86(0.01)$ & $0.85(0.00)$ & $0.85(0.01)$ & .4608 \\
\hline Smoker, \% & 25.21 & 32.21 & 36.24 & .3241 \\
\hline Physical activity, \% & 31.85 & 39.60 & 29.11 & .0546 \\
\hline Drinker, \% & 32.58 & 32.75 & 43.83 & .0418 \\
\hline High instrumental support, ${ }^{\#}$ & 36.63 & 28.56 & 32.62 & .4168 \\
\hline High emotional support," \% & 49.36 & 38.16 & 40.61 & .3220 \\
\hline High John Henryism, $^{* *} \%$ & 46.33 & 47.41 & 47.66 & .9869 \\
\hline High stress, ${ }^{* *} \%$ & 48.39 & 52.91 & 54.46 & .7589 \\
\hline Hypertension, \% & 11.12 & 29.18 & 19.78 & .0018 \\
\hline
\end{tabular}

$\mathrm{HH}=$ household; SE = standard error; WHR = waist-to-hip ratio.

Data were weighted for oversampling and nonresponse.

* Rao-Scott $\chi^{2}$ test for comparison (\%), $t$ test (mean) of difference.

$\dagger$ Measured in 2001 via Event History Calendar.

$¥$ Birth to 18 years.

$\S$ Birth to 13 years.

" US Census Occupations, (see [7] for full citation).

๙ Hollingshead Scale (see [7] for full citation).

\# Support always/most of the time.

** Score above the median. 
Table 4

Childhood public assistance and adult hypertension among African American men: the Pitt County, North Carolina, Study

\begin{tabular}{|c|c|c|c|c|c|}
\hline \multirow[t]{2}{*}{ Childhood public assistance } & Model $1^{*}$ & Model $2^{\dagger}$ & Model $3^{\ddagger}$ & Model 4 & Model $5^{\|}$ \\
\hline & \multicolumn{5}{|l|}{ OR $(95 \% \mathrm{CI})$} \\
\hline Public assistance & $1.15(0.54-2.48)$ & $1.01(0.43-2.37)$ & $1.00(0.42-2.38)$ & $1.02(0.42-2.49)$ & $0.92(0.39-2.16)$ \\
\hline No public assistance/no household deprivation & $0.95(0.53-1.70)$ & $0.96(0.52-1.76)$ & $0.98(0.53-1.81)$ & $0.96(0.51-1.81)$ & $1.06(0.56-2.01)$ \\
\hline No public assistance/household deprivation & 1.00 (Referent) & 1.00 (Referent) & 1.00 (Referent) & 1.00 (Referent) & 1.00 (Referent) \\
\hline
\end{tabular}

Data weighted for oversampling and non-response.

* Age-adjusted.

$\dagger$ Additionally adjusted for childhood socio-familial factors: family structure and parental guardian stability, education and occupation.

$\ddagger$ Additionally adjusted for socioeconomic factors in 1988: marital status, employment, education and occupation.

Additionally adjusted for psychosocial factors in 1988: John Henryism, instrumental and emotional support and perceived stress.

" Additionally adjusted for lifestyle factors in 1988: body mass index, waist-hip ratio, smoking, strenuous exercise, and alcohol use.

A statistically significant inverse association was found between childhood public assistance and hypertension for African American women (Table 5). Women who resided from birth to 13 years of age in families that received public assistance had $70 \%$ decreased odds of hypertension compared with those from similarly disadvantaged families that did not receive public assistance; unadjusted $\mathrm{OR}=0.30,95 \% \mathrm{CI}: 0.14-0.68$. The relationship between childhood public assistance and hypertension in 1988 persisted in all covariate-adjusted models, with the fully adjusted model yielding a $66 \%$ decreased odds of hypertension for women, $\mathrm{OR}_{\mathrm{adj}}=0.34,95 \%$ CI: 0.14-0.83. Women who grew up in families that neither received public assistance nor experienced household deprivation had $40 \%$ decreased odds of hypertension compared with women from socioeconomically deprived households who did not receive public assistance; unadjusted $\mathrm{OR}=0.60,95 \% \mathrm{CI}$ : $0.39-0.93$. No significant association was detected after full covariate adjustment, $\mathrm{OR}_{\mathrm{adj}}=0.84,95 \% \mathrm{CI}: 0.51-1.40$. In the Appendix, we provide tables that include more detailed statistical models.

\section{Discussion}

African American women who received needed public assistance in childhood had a $66 \%$ decreased odds of hypertension compared with those with equal need, but who did not receive public assistance. This association was independent of sociofamilial factors in childhood and socioeconomic, demographic, lifestyle, and psychosocial characteristics in adulthood. We found no statistically significant association between public assistance, household deprivation, and risk for hypertension among African American men before or after statistical adjustment. The observed sex difference, however, is consistent with previous research reporting the relationship between childhood socioeconomic position and adult BP to hold only for women [19,20].

That childhood public assistance was associated with lower odds for hypertension relative to women who reported no childhood material deprivation is an interesting finding. Since selection bias due to loss to follow-up has been demonstrated to be minimal among PCS women, our results suggest that the added socioeconomic benefit provided by public assistance may have negated some of the adverse impact of childhood household material deprivation on hypertension by early-middle adulthood. Studies designed to replicate this finding in other communitybased samples of African Americans are needed. However, our findings of a potential long-term cardiovascular health benefit of childhood participation in a federal anti-poverty program are consistent with the documented positive association between childhood socioeconomic position and adult cardiovascular health in populations in other settings [21-23].

Hypertension has its origins in early childhood [22,24], and socioeconomic resources are known to influence BP and prehypertension in children as young as 5 and 6 years of age [25]. The potentiation of the inverse association between age and BP, by an impoverished childhood, suggests a latent effect where early life disadvantage places individuals on an accelerated trajectory to develop hypertension in early-middle adulthood [23,26]. Public assistance programs that reduce the multiple socioeconomic disadvantages poor families face could help decelerate otherwise fast, age-related hypertension trajectories among children who grow up in these households.

Sex differences in the associations between childhood socioeconomic indicators and elevated BP in adulthood remain unexplained by known risk factors. Childhood socioeconomic disadvantage has been shown to more strongly influence modifiable factors for elevated BP (e.g., lower physical activity and physical fitness [27,28], increased weight gain [29], and body mass [30]) among girls than boys. Although childhood body mass was not measured in this study, the higher BMI observed at mid-life for PCS women, relative to men, probably has origins in early life socioeconomic disadvantage [31]. Therefore, sex differences in our reported association between childhood receipt of public assistance and adult hypertension could be due, at least in part, to sex differences in the relationship between early life socioeconomic position and body mass, given that the latter is a major risk factor for elevated BP [25]. The absence of an observed association, for men, between childhood public assistance and laterlife hypertension could also be due to selection bias, given that loss to follow-up was inversely associated with socioeconomic

Table 5

Childhood public assistance and adult hypertension among African American women: the Pitt County, North Carolina, Study

\begin{tabular}{|c|c|c|c|c|c|}
\hline \multirow[t]{2}{*}{ Childhood public assistance } & Model $1^{*}$ & Model $2^{\dagger}$ & Model $3^{\ddagger}$ & Model 4 & Model $5 \|$ \\
\hline & \multicolumn{5}{|l|}{ OR $(95 \% \mathrm{CI})$} \\
\hline Public assistance & $0.35(0.16-0.78)$ & $0.35(0.16-0.78)$ & $0.34(0.15-0.79)$ & $0.35(0.15-0.80)$ & $0.34(0.14-0.83)$ \\
\hline No public assistance/no household deprivation & $0.82(0.52-1.31)$ & $0.88(0.54-1.42)$ & $0.88(0.54-1.44)$ & $0.91(0.55-1.49)$ & $0.84(0.51-1.40)$ \\
\hline No public assistance/household deprivation & 1.00 (Referent) & 1.00 (Referent) & 1.00 (Referent) & 1.00 (Referent) & 1.00 (Referent) \\
\hline
\end{tabular}

Data weighted for oversampling and non-response.

* Age-adjusted.

Additionally adjusted for childhood socio-familial factors: family structure and parental guardian stability, education and occupation.

$\ddagger$ Additionally adjusted for socioeconomic factors in 1988: marital status, employment, education and occupation.

Additionally adjusted for psychosocial factors in 1988: John Henryism, instrumental and emotional support and perceived stress.

॥ Additionally adjusted for lifestyle factors in 1988: body mass index, waist-hip ratio, smoking, strenuous exercise, and alcohol use. 
disadvantage; however, weighting our analyses for nonresponse should have mitigated the impact of this source of bias.

To our knowledge, this is the first study to document a longterm, sex-specific cardiovascular benefit of childhood receipt of public assistance among socioeconomically disadvantaged African American women. The fact that our study findings are based on an observational study, rather than a randomized trial, precludes unqualified statements about causal relationships. However, our findings are consistent with a growing body of evidence attesting to substantive and long-term health benefits of social policies that mitigate the well-known adverse effects of early childhood material and social deprivation [32].

Our retrospective assessment of childhood receipt of public assistance did not collect information on the types of public assistance (e.g., food stamps, Medicaid, public housing, and so on) study participants received in childhood; hence, we are unable to identify whether some types of public assistance were more impactful than others. This is a potentially important question for future research.

Study limitations include potential recall bias because of our retrospective study design. However, in addition to our use of the EHC $[14,15]$ to aid recall accuracy, we believe that weighting the estimates to account for differential nonresponse, along with the low probability of systematic misclassification on the exposure by hypertensive status, minimizes the contribution of recall bias on our results. Moreover, validation studies have found decades-long recollection of discrete and objective early life socioeconomic experiences to be reasonably accurate and reliable [33-36].

Receipt of public assistance during childhood may be correlated with, or alternatively, be a proxy for other early life determinants of adult hypertension that we did not adjust for in our analyses, that is, childhood neighborhood deprivation [37], childhood maltreatment $[38,39]$, infant birth weight, breastfeeding duration, childhood BMI, and environmental tobacco smoke exposure [25], among others, including number of children in the household. It is also the case that statistical adjustment for some or all of these unmeasured mediators could lead to over-adjustment bias [40]. Finally, misclassification of covariates due to our reliance on somewhat crude lifestyle measures (e.g., physical activity and alcohol status) could have biased our results, but we believe that such bias is likely to be random in nature.

Our research findings suggest that investments in social policies that reduce early life socioeconomic disadvantage provide a longterm cardiovascular benefit for African Americans, especially women, who grow up in disadvantaged households. Furthermore, these social investments in public assistance programs for families in need could also reduce the nation's social and economic burden from hypertension, which by recent estimates, costs the nation approximately $\$ 46$ billion per year [8].

\section{Acknowledgments}

This study was supported by the National Institute on Minority Health and Health Disparities (NIMHD/NIH) grant K22MD006133 to Dr. Barrington. The Pitt County Study was supported by the National Heart, Lung, and Blood Institute (NHLBI/NIH) grants R01HL033211 and R01HL065645 to Dr. James.

\section{References}

[1] DeNavas-Walt C, Proctor BD. Income and Poverty in the United States: 2014. Washington, DC: U.S. Census Bureau; 2015.

[2] Irving SK, Loveless T. Dynamics of Economic Well-Being: Participation in Government Programs, 2009-2012: Who Gets Assistance. Washington, DC: U.S. Census Bureau; 2015.

[3] Almond D, Hoynes HW, Schanzenbach DW. Inside the war on poverty: the impact of food stamps on birth outcomes. Rev Econ Stat 2011;93(2):387-403.
[4] Lee BJ, Mackey-Bilaver L. Effects of WIC and Food Stamp Program participation on child outcomes. Child Youth Serv Rev 2007;29(4):501-17.

[5] Jackson MI. Early childhood WIC participation, cognitive development and academic achievement. Soc Sci Med 2015;126:145-53.

[6] Hoynes HW. Long Run Impacts of Childhood Access to the Safety Net. Cambridge, MA: National Bureau of Economic Research; 2012.

[7] U.S. Bureau of Labor Statistics. Labor Force Characteristics by Race and Ethnicity, 2013. Washington, DC: BLS Reports; 2014.

[8] Mozaffarian D, Benjamin EJ, Go AS, Arnett DK, Blaha MJ, Cushman M, et al. Heart disease and stroke statistics-2015 update: a report from the American Heart Association. Circulation 2015;131(4):e29-322.

[9] Roberts CB, Vines AI, Kaufman JS, James SA. Cross-sectional association between perceived discrimination and hypertension in African-American men and women: the Pitt County Study. Am J Epidemiol 2008;167(5):624-32.

[10] Curtis AB, Strogatz DS, James SA, Raghunathan TE. The contribution of baseline weight and weight gain to blood pressure change in African Americans: the Pitt County Study. Ann Epidemiol 1998:8(8):497-503.

[11] James SA, Jamjoum L, Raghunathan TE, Strogatz DS, Furth ED, Khazanie PG Physical activity and NIDDM in African-Americans. The Pitt County Study. Diabetes Care 1998;21(4):555-62.

[12] James SA, Van Hoewyk J, Belli RF, Strogatz DS, Williams DR, Raghunathan TE Life-course socioeconomic position and hypertension in African American men: the Pitt County Study. Am J Public Health 2006;96(5):812-7.

[13] Strogatz DS, James SA, Haines PS, Elmer PJ, Gerber AM, Browning SR, et al. Alcohol consumption and blood pressure in black adults: the Pitt County Study. Am J Epidemiol 1991;133(5):442-50.

[14] Belli RF. The structure of autobiographical memory and the event history calendar: potential improvements in the quality of retrospective reports in surveys. Memory 1998;6(4):383-406.

[15] Belli RF, Shay WL, Stafford FP. Event history calendars and question list surveys a direct comparison of interviewing methods. Public Opin Q 2001:65(1):45-74.

[16] James SA, Keenan NL, Strogatz DS, Browning SR, Garrett JM. Socioeconomic status, John Henryism, and blood pressure in black adults. The Pitt County Study. Am J Epidemiol 1992;135(1):59-67.

[17] Strogatz DS, Croft JB, James SA, Keenan NL, Browning SR, Garrett JM, et al. Social support, stress, and blood pressure in black adults. Epidemiology 1997;8(5):482-7.

[18] Analysis of complex sample survey data using the SURVEYMEANS and SURVEYREG procedures and macro coding. In: Bergland PA, editor. Proceedings of the Twenty-Seventh Annual SAS Users Group International Conference. Cary, NC: SAS Institute Inc; 2002.

[19] Janicki-Deverts D, Cohen S, Matthews KA, Jacobs Jr DR. Sex differences in the association of childhood socioeconomic status with adult blood pressure change: the CARDIA study. Psychosom Med 2012:74(7):728-35.

[20] Schumann B, Kluttig A, Tiller D, Werdan K, Haerting J, Greiser KH. Association of childhood and adult socioeconomic indicators with cardiovascular risk factors and its modification by age: the CARLA Study 2002-2006. BMC Public Health 2011;11:289.

[21] Power C, Atherton K, Strachan DP, Shepherd P, Fuller E, Davis A, et al. Lifecourse influences on health in British adults: effects of socio-economic position in childhood and adulthood. Int J Epidemiol 2007;36(3):532-9.

[22] Kivimaki M, Smith GD, Elovainio M, Pulkki L, Keltikangas-Jarvinen L, Talttonen L, et al. Socioeconomic circumstances in childhood and blood pressure in adulthood: the cardiovascular risk in young Finns study. Ann Epidemiol 2006;16(10):737-42.

[23] Hardy R, Kuh D, Langenberg C, Wadsworth ME. Birthweight, childhood social class, and change in adult blood pressure in the 1946 British birth cohort. Lancet 2003:362(9391):1178-83.

[24] Chen X, Wang Y. Tracking of blood pressure from childhood to adulthood: a systematic review and meta-regression analysis. Circulation 2008;117(25):3171-80.

[25] van den Berg G, van Eijsden M, Galindo-Garre F, Vrijkotte TG, Gemke R]. Explaining socioeconomic inequalities in childhood blood pressure and prehypertension: the ABCD study. Hypertension 2013;61(1):35-41.

[26] Lawlor DA, Smith GD. Early life determinants of adult blood pressure. Curr Opin Nephrol Hypertens 2005;14(3):259-64.

[27] Bohr AD, Brown DD, Laurson KR, Smith PJ, Bass RW. Relationship between socioeconomic status and physical fitness in junior high school students. J Sch Health $2013: 83(8): 542-7$.

[28] Fairclough SJ, Boddy LM, Hackett AF, Stratton G. Associations between children's socioeconomic status, weight status, and sex, with screen-based sedentary behaviours and sport participation. Int J Pediatr Obes 2009;4(4):299-305.

[29] Balistreri KS, Van Hook J. Trajectories of overweight among US school children: a focus on social and economic characteristics. Matern Child Health 2011:15(5):610-9.

[30] Pudrovska T, Reither EN, Logan ES, Sherman-Wilkins KJ. Gender and reinforcing associations between socioeconomic disadvantage and body mass over the life course. J Health Soc Behav 2014:55(3):283-301.

[31] James SA, Fowler-Brown A, Raghunathan TE, Van Hoewyk J. Life-course socioeconomic position and obesity in African American Women: the Pitt County Study. Am J Public Health 2006;96(3):554-60.

[32] Schoeni RF, House JS, Kaplan GA, Pollack $H$, editors. Making Americans Healthier: Social and Economic Policy as Health Policy. New York: Russell Sage Foundation; 2008. 
[33] Yancura LA, Aldwin CM. Stability and change in retrospective reports of childhood experiences over a 5-year period: findings from the Davis Longitudinal Study. Psychol Aging 2009;24(3):715-21.

[34] Krieger N, Okamoto A, Selby JV. Adult female twins' recall of childhood social class and father's education: a validation study for public health research. Am J Epidemiol 1998;147(7):704-8.

[35] Berney LR, Blane DB. Collecting retrospective data: accuracy of recall after 50 years judged against historical records. Soc Sci Med 1997;45(10):1519-25.

[36] Batty GD, Lawlor DA, Macintyre S, Clark H, Leon DA. Accuracy of adults' recall of childhood social class: findings from the Aberdeen children of the 1950s study. J Epidemiol Community Health 2005;59(10):898-903.
[37] Johnson RC, Schoeni RF. Early-life origins of adult disease: national longitudinal population-based study of the United States. Am J Public Health 2011;101(12):2317-24.

[38] Riley EH, Wright RJ, Jun HJ, Hibert EN, Rich-Edwards JW. Hypertension in adult survivors of child abuse: observations from the Nurses' Health Study II. J Epidemiol Community Health 2010;64(5):413-8.

[39] Springer KW, Sheridan J, Kuo D, Carnes M. Long-term physical and mental health consequences of childhood physical abuse: results from a large population-based sample of men and women. Child Abuse Negl 2007:31(5):517-30.

[40] Schisterman EF, Cole SR, Platt RW. Overadjustment bias and unnecessary adjustment in epidemiologic studies. Epidemiology 2009;20(4):488-95. 
Appendix

Appendix Table 1

Regression coefficients for public assistance and adult hypertension for men

\begin{tabular}{|c|c|c|c|c|c|c|c|c|c|c|c|c|}
\hline \multirow[t]{3}{*}{ Variable } & \multirow{2}{*}{\multicolumn{2}{|c|}{$\begin{array}{l}\text { Crude } \\
n=405\end{array}$}} & \multirow{2}{*}{\multicolumn{2}{|c|}{$\frac{\text { Model } 1}{n=405}$}} & \multirow{2}{*}{\multicolumn{2}{|c|}{$\frac{\text { Model } 2}{n=405}$}} & \multirow{2}{*}{\multicolumn{2}{|c|}{$\frac{\text { Model } 3}{n=404}$}} & \multirow{2}{*}{\multicolumn{2}{|c|}{$\frac{\text { Model } 4}{n=402}$}} & \multirow{2}{*}{\multicolumn{2}{|c|}{$\frac{\text { Model } 5}{n=401}$}} \\
\hline & & & & & & & & & & & & \\
\hline & Beta & SE & Beta & SE & Beta & SE & Beta & SE & Beta & SE & Beta & SE \\
\hline Intercept & -0.68 & 0.16 & -3.26 & 0.78 & -2.79 & 0.88 & -3.08 & 0.99 & -2.84 & 1.02 & -5.58 & 1.49 \\
\hline Public assistance & -0.19 & 0.38 & 0.14 & 0.39 & 0.01 & 0.44 & 0.00 & 0.44 & 0.02 & 0.46 & -0.09 & 0.44 \\
\hline No public assistance/no deprivation & -0.25 & 0.28 & -0.06 & 0.30 & -0.04 & 0.31 & -0.02 & 0.32 & -0.04 & 0.32 & 0.06 & 0.33 \\
\hline Age & & & 0.07 & 0.02 & 0.07 & 0.02 & 0.07 & 0.02 & 0.07 & 0.02 & 0.06 & 0.02 \\
\hline Intact family & & & & & -0.37 & 0.39 & -0.38 & 0.40 & -0.42 & 0.41 & -0.52 & 0.40 \\
\hline Two adult household & & & & & -0.16 & 0.33 & -0.18 & 0.34 & -0.17 & 0.34 & -0.07 & 0.34 \\
\hline Parental education, missing & & & & & 0.19 & 0.31 & 0.13 & 0.32 & 0.17 & 0.32 & 0.32 & 0.34 \\
\hline Parental education, $>$ HS & & & & & 0.47 & 0.35 & 0.49 & 0.36 & 0.55 & 0.36 & 0.67 & 0.37 \\
\hline Parental occupation, skilled & & & & & -0.79 & 0.42 & -0.76 & 0.44 & -0.80 & 0.45 & -0.81 & 0.44 \\
\hline Parental occupation, farmer & & & & & -0.03 & 0.32 & -0.05 & 0.33 & -0.10 & 0.34 & 0.01 & 0.36 \\
\hline Married & & & & & & & 0.09 & 0.27 & 0.06 & 0.27 & 0.00 & 0.31 \\
\hline Unemployed & & & & & & & 0.40 & 0.53 & 0.50 & 0.54 & 0.68 & 0.52 \\
\hline Education HS & & & & & & & -0.03 & 0.34 & -0.07 & 0.34 & -0.05 & 0.35 \\
\hline Education $>$ HS & & & & & & & -0.25 & 0.38 & -0.21 & 0.38 & -0.04 & 0.39 \\
\hline Occupation, operatives & & & & & & & 0.41 & 0.36 & 0.37 & 0.37 & 0.32 & 0.38 \\
\hline Occupation craft/white collar & & & & & & & 0.19 & 0.37 & 0.10 & 0.38 & -0.22 & 0.39 \\
\hline High John Henryism & & & & & & & & & -0.18 & 0.27 & -0.16 & 0.28 \\
\hline Instrumental support & & & & & & & & & 0.28 & 0.32 & 0.16 & 0.34 \\
\hline Emotional support & & & & & & & & & 0.21 & 0.31 & 0.34 & 0.33 \\
\hline High stress & & & & & & & & & -0.23 & 0.28 & -0.13 & 0.30 \\
\hline BMI & & & & & & & & & & & 0.10 & 0.03 \\
\hline WHR_Q2 & & & & & & & & & & & -0.32 & 0.43 \\
\hline WHR_Q3 & & & & & & & & & & & 0.96 & 0.37 \\
\hline WHR_Q4 & & & & & & & & & & & 0.17 & 0.43 \\
\hline Smoker & & & & & & & & & & & 0.05 & 0.30 \\
\hline Physical activity & & & & & & & & & & & -0.04 & 0.28 \\
\hline Drinker & & & & & & & & & & & 0.01 & 0.30 \\
\hline
\end{tabular}

$\mathrm{SE}=$ standard error; WHR = waist-to-hip ratio.

Data weighted for oversampling and non-response. 
Appendix Table 2

Regression coefficients for public assistance and adult hypertension for women

\begin{tabular}{|c|c|c|c|c|c|c|c|c|c|c|c|c|}
\hline \multirow[t]{3}{*}{ Variable } & \multirow{2}{*}{\multicolumn{2}{|c|}{$\begin{array}{l}\text { Crude model } \\
n=737\end{array}$}} & \multirow{2}{*}{\multicolumn{2}{|c|}{$\frac{\text { Model } 1}{n=737}$}} & \multirow{2}{*}{\multicolumn{2}{|c|}{$\frac{\text { Model } 2}{n=736}$}} & \multirow{2}{*}{\multicolumn{2}{|c|}{$\frac{\text { Model } 3}{n=736}$}} & \multirow{2}{*}{\multicolumn{2}{|c|}{$\frac{\text { Model } 4}{n=736}$}} & \multirow{2}{*}{\multicolumn{2}{|c|}{$\frac{\text { Model } 5}{n=727}$}} \\
\hline & & & & & & & & & & & & \\
\hline & Beta & SE & Beta & SE & Beta & SE & Beta & SE & Beta & SE & Beta & SE \\
\hline Intercept & -0.89 & 0.12 & -4.13 & 0.59 & -4.00 & 0.63 & -4.12 & 0.75 & -4.38 & 0.81 & -8.27 & 1.09 \\
\hline Public assistance & -1.19 & 0.41 & -1.04 & 0.41 & -1.05 & 0.41 & -1.07 & 0.42 & -1.05 & 0.42 & -1.09 & 0.46 \\
\hline No public assistance/no deprivation & -0.51 & 0.22 & -0.20 & 0.24 & -0.13 & 0.25 & -0.13 & 0.25 & -0.10 & 0.25 & -0.17 & 0.26 \\
\hline Age & & & 0.09 & 0.01 & 0.08 & 0.02 & 0.09 & 0.02 & 0.09 & 0.02 & 0.08 & 0.02 \\
\hline Intact family & & & & & 0.20 & 0.29 & 0.16 & 0.29 & 0.17 & 0.30 & 0.19 & 0.31 \\
\hline Two adult household & & & & & -0.09 & 0.25 & -0.03 & 0.25 & -0.06 & 0.25 & 0.06 & 0.26 \\
\hline Parental education, missing & & & & & -0.11 & 0.25 & -0.11 & 0.26 & -0.18 & 0.27 & -0.12 & 0.27 \\
\hline Parental education, $>$ HS & & & & & -0.58 & 0.31 & -0.55 & 0.32 & -0.59 & 0.32 & -0.50 & 0.35 \\
\hline Parental occupation, skilled & & & & & -0.19 & 0.33 & -0.20 & 0.33 & -0.14 & 0.34 & -0.27 & 0.37 \\
\hline Parental occupation, farmer & & & & & -0.01 & 0.27 & -0.02 & 0.27 & -0.03 & 0.28 & -0.09 & 0.29 \\
\hline Married & & & & & & & 0.05 & 0.23 & 0.20 & 0.24 & 0.31 & 0.25 \\
\hline Unemployed & & & & & & & 0.45 & 0.28 & 0.39 & 0.28 & 0.13 & 0.31 \\
\hline Education HS & & & & & & & 0.19 & 0.28 & 0.20 & 0.28 & 0.37 & 0.29 \\
\hline Education $>\mathrm{HS}$ & & & & & & & 0.04 & 0.37 & 0.07 & 0.37 & 0.14 & 0.39 \\
\hline Occupation, operatives & & & & & & & -0.22 & 0.26 & -0.17 & 0.26 & -0.22 & 0.28 \\
\hline Occupation, craft/white collar & & & & & & & -0.21 & 0.33 & -0.17 & 0.33 & -0.04 & 0.34 \\
\hline High John Henryism & & & & & & & & & 0.05 & 0.21 & 0.18 & 0.22 \\
\hline Instrumental support & & & & & & & & & -0.80 & 0.29 & -0.72 & 0.32 \\
\hline Emotional support & & & & & & & & & 0.19 & 0.25 & 0.13 & 0.29 \\
\hline High stress & & & & & & & & & 0.30 & 0.23 & 0.25 & 0.24 \\
\hline BMI & & & & & & & & & & & 0.10 & 0.02 \\
\hline WHR_Q2 & & & & & & & & & & & 0.37 & 0.36 \\
\hline WHR_Q3 & & & & & & & & & & & 0.74 & 0.36 \\
\hline WHR_Q4 & & & & & & & & & & & 1.17 & 0.36 \\
\hline Smoker & & & & & & & & & & & 0.51 & 0.27 \\
\hline Physical activity & & & & & & & & & & & -0.39 & 0.25 \\
\hline Drinker & & & & & & & & & & & 0.42 & 0.25 \\
\hline
\end{tabular}

SE = standard error; WHR = waist-to-hip ratio.

Data weighted for oversampling and non-response. 